\title{
Low birthweight babies with oesophageal atresia or tracheo-oesophageal fistula
}

\author{
FRANCESCO COZZI* and ANDREW W. WILKINSON \\ From the Department of Paediatric Surgery, Institute of Child Health, London
}

\begin{abstract}
Cozzi, F., and Wilkinson, A. W. (1975). Archives of Disease in Childhood, 50, 791. Low birthweight babies with oesophageal atresia or tracheo-oesophageal fistula. Of 142 patients of known gestation with oesophageal atresia or tracheooesophageal fistula, $21 \%$ were preterm with a mean weight of $2 \mathrm{~kg}, 19 \%$ were smallfor-dates with a mean weight of $2 \cdot 23 \mathrm{~kg}$, and the remaining $60 \%$ were born at term and weighed more than $2.5 \mathrm{~kg}$. There were almost five times as many preterm and almost eight times as many small-for-dates infants as in a normal population. Respiratory distress syndrome and additional severe congenital anomalies were commoner in babies of short gestational age, and pneumonia was more common in small-fordates babies.
\end{abstract}

The mortality and morbidity of infants with oesophageal atresia are related to three main factors: low birthweight, additional congenital anomalies, and pneumonia (Waterston, Bonham Carter, and Aberdeen, 1962; Koop and Hamilton, 1965; Cozzi and Wilkinson, 1967, unpublished, 1975; Myers, 1974). On the basis of these three factors the risk to survival was classified into groups A, B, and C by Waterston et al. (1962), and the use of this classification and modifications of it has helped considerably to define the problems which the surgeon and the baby face in oesophageal atresia. Small babies have often been called preterm regardless of gestational age, but some problems of the newborn are more related to maturity than to birthweight. We have reviewed a series of 153 babies with oesophageal atresia treated in one unit between 1959 and 1973 and have studied the relations between birthweight, gestational age, and other factors which influence survival and their bearing on the choice of treatment.

\section{Patients and methods}

Between January 1959 and December 1973, 153 patients with oesophageal atresia or tracheo-oesophageal fistula were admitted to the Professorial Surgical Unit of The Hospital for Sick Children, London. The

Received 31 January 1975.

^Present address: Department of Paediatric Surgery, Children's Hospital, University of Rome. gestational age of 11 babies was not known; these patients will not be discussed, though 7 had a birthweight below $2 \cdot 5 \mathrm{~kg}$.

The birthweights of the remaining 142 patients were plotted against weeks of gestation using the intrauterine growth curves of Lubchenco et al. (1963). In agreement with the Second European Congress of Perinatal Medicine (Working Party, 1971) any infant born before 37 completed weeks of gestation (instead of 38 weeks, as decided in 1967 by the American Academy of Pediatrics) is called a preterm infant, while those born after 37 weeks are called term infants. Any baby born at term who weighed $2.5 \mathrm{~kg}$ or less (as recommended by the World Health Organization, 1961) was regarded as a low weight baby (small-for-dates), whereas if Lubchenco's 10th centile (Lubchenco et al., 1963) is used, a greater number of babies should be considered as suffering from intrauterine growth retardation.

Intrauterine growth. By these definitions $21 \%$ of the patients ( 16 boys, 14 girls) were preterm infants with a mean weight of $20.08 \mathrm{~kg}, 19 \%$ (17 boys, 10 girls) were small-for-dates with a mean weight of $2 \cdot 23 \mathrm{~kg}$, and $60 \%$ ( 43 boys, 42 girls) were born at term and weighed more than $2.5 \mathrm{~kg}$ (mean weight $3.05 \mathrm{~kg}$ ) (Fig. 1). The large number plotted on the 40th week includes patients who were specifically stated to be born at 40 weeks and others who were simply said to have been born at term. This series of infants with oesophageal atresia included nearly five times as many preterm babies and eight times as many babies who were small-for-dates as would be found in a population of normal neonates (Butler and Bonham, 1963). The birthweight of the majority of term patients was well below the 50 th centile, whereas 


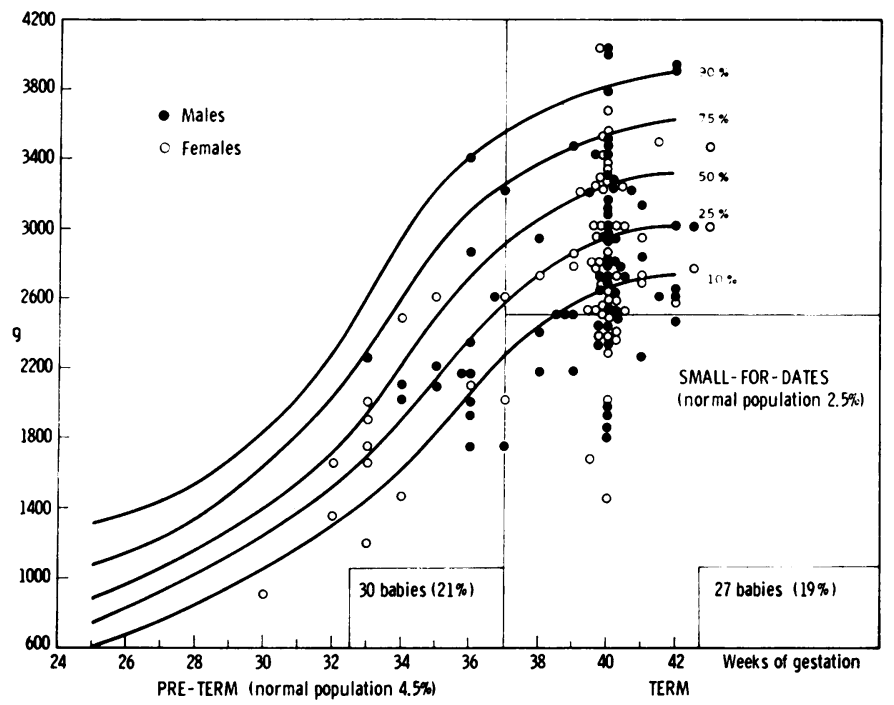

FIG. 1.-Birthweight and gestation.

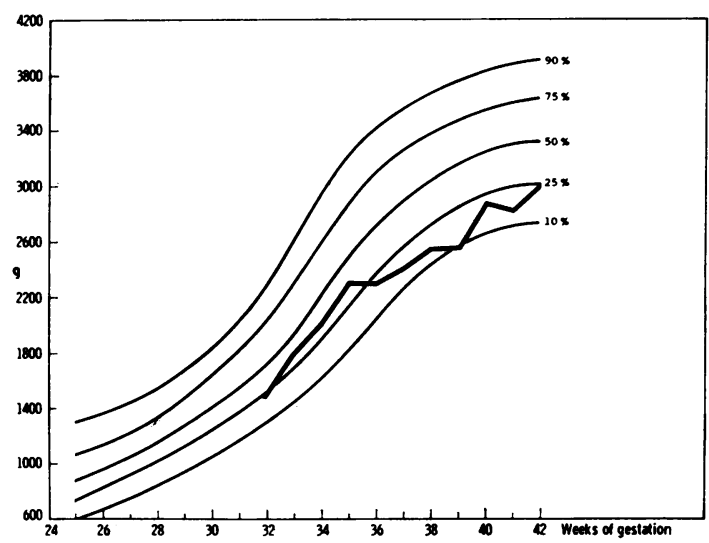

FIG. 2.-Intrauterine growth of babies with oesophageal atresia.

the infants with a short gestational age had a birthweight which did not deviate much from the standard growth. If the mean weight for each week of gestation is considered (Fig. 2) it can be seen that intrauterine growth retardation becomes more evident at about 36 weeks when the mean weight is below the 25th centile.

Respiratory problems. In 41 out of 142 patients $(29 \%)$ there were respiratory complications. $x$-ray opacity of one or more lobes was classified as pneumonia and no attempt was made to distinguish between collapse and consolidation. By this definition 30 infants had pneumonia and the right upper lobe was most often involved. 12 babies had respiratory distress, a term used as a clinical diagnosis to cover all sorts of respiratory disorders not related to the tracheo-oesophageal fistula; one of these also had pneumonia as defined above. In babies dying of respiratory distress, hyaline membrane disease was found in 3 at necropsy, massive pulmonary haemorrhage in 2, meconium aspiration in 2, and pulmonary hypoplasia in 2 (associated with renal agenesis and low-set ears-Potter's syndrome).

Pneumonia was more frequently diagnosed in term infants, and among these a significantly higher incidence was found in small-for-dates babies than in babies of normal weight $\left(\chi^{2}=4.4 ; 0.05>P>0.01\right)$. Respiratory distress was significantly more frequent in preterm than in term infants $\left(x^{2}=3.97 ; 0.05>\mathrm{P}>0.01\right)$ (Fig. 3).

Associated anomalies. Another severe anomaly, which would of itself threaten or prevent survival, was found in 44 patients (30\%) (Fig. 4). In term infants the incidence of associated severe anomalies was not different from that in babies without oesophageal atresia, whereas such anomalies were more frequent in preterm babies $\left(\chi^{2}=15 ; \mathrm{P}<0.001\right)$. Commonest were anorectal abnormalities, and about half occurred in babies with a short gestational age $\left(\chi^{2}=7 \cdot 9\right.$; $0.01>P>0.001$ ).

Deaths. Of the $\mathbf{3 0}$ babies born after less than 37 weeks' gestation only 8 survived (26\%). 1 of these 16 was born between 1959 and 1967, and the remaining 7 were out of 14 born between 1967 and 1973. 3 of these survivors were in a group of 6 babies who weighed more than $2.5 \mathrm{~kg}$. There were 27 small-for-dates babies of whom 10 survived $(37 \%)$. The other 85 babies weighed more than $2.5 \mathrm{~kg}$, and were born after 37 or more weeks' gestation. Only 21 of these died, a survival rate of $75 \cdot 3 \%$. 


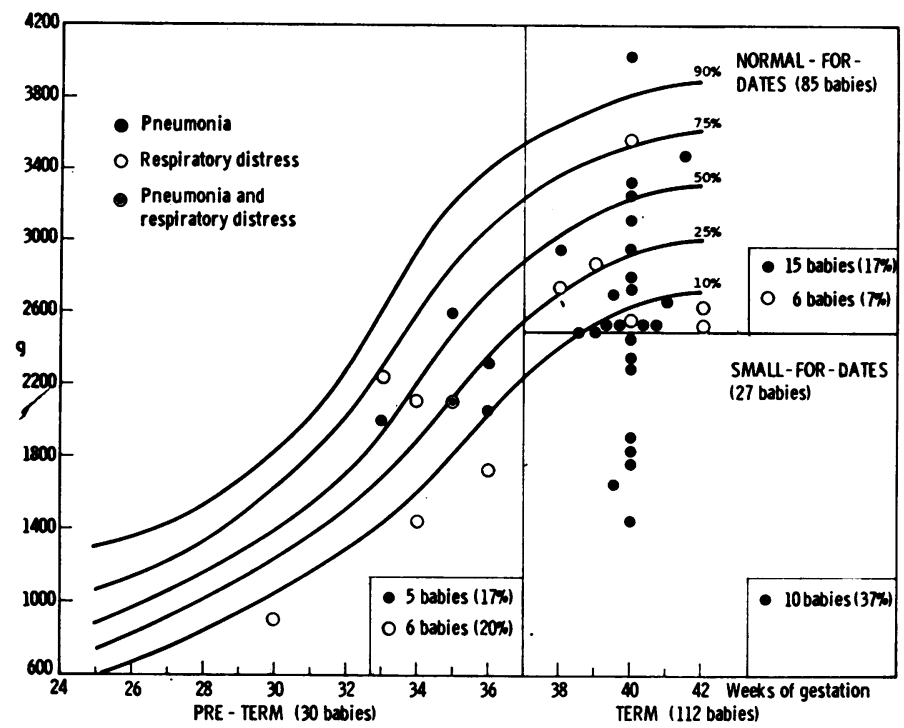

FIG. 3.-Birthweights of 41 babies with oesophageal atresia and respiratory problems plotted against weeks of gestation.

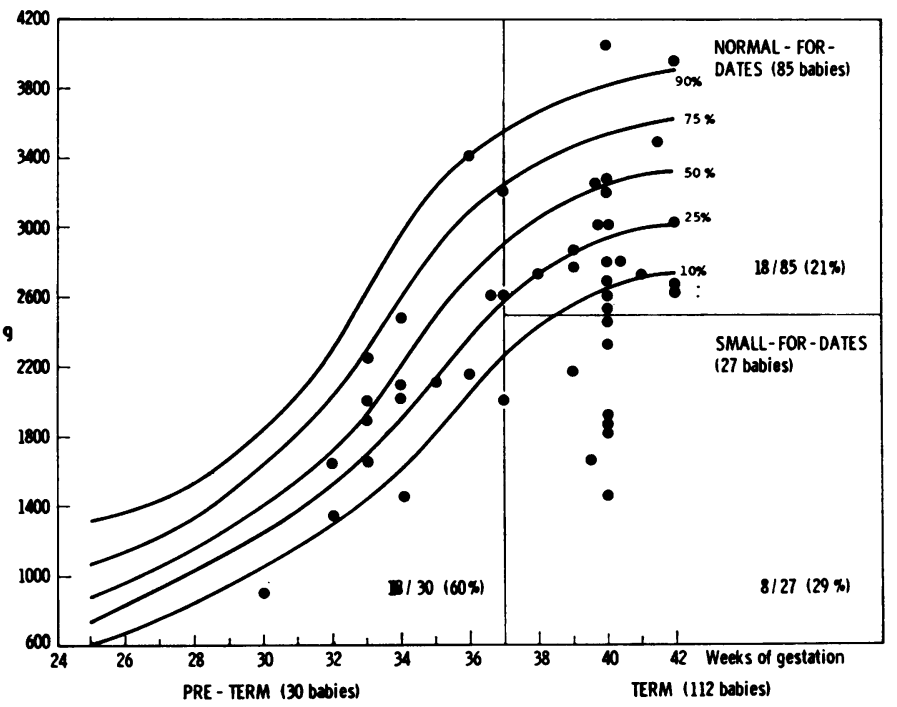

FrG. 4.-Birthweights of 44 babies with oesophageal atresia and severe additional anomalies plotted against weeks of gestation.

\section{Treatment}

Of 142 patients, 5 died before surgery could be undertaken. In 6 patients with tracheo-oesophageal fistula without atresia the fistula was divided and all did well.

Of the remaining 131 babies, 90 were treated by division of the fistula and anastomosis of the oesophagus and in 41 the operative treatment was done in stages. When the general condition of the child was good and the gap between the two segments of the oesophagus was small, the fistula was divided and closed and a primary anastomosis was made (49 patients), regardless of the birthweight of the baby. When the general condition of the child was poor, or the gap between the segments of the oesophagus was too wide, the fistula was 
divided and closed as a primary procedure. Delayed anastomosis was successful in 10 out of 13 patients. When there was oesophageal atresia without tracheo-oesophageal fistula a cervical oesophagostomy and a gastrostomy for feeding were made and the gap in the oesophagus was later bridged with a segment of colon (5 small-fordates, 1 preterm, and 2 large term babies).

A primary anastomosis was made in a somewhat lower proportion (18 out of $27,67 \%$ ) of small-fordates babies (Table I) compared with term babies

\section{TABLE I}

Intrauterine growth and operative procedures in 131 babies with oesophageal atresia

\begin{tabular}{|c|c|c|c|c|}
\hline & \multicolumn{2}{|c|}{ Primary repair } & \multicolumn{2}{|c|}{$\begin{array}{l}\text { Staged } \\
\text { procedures }\end{array}$} \\
\hline & $\begin{array}{l}\text { No. of } \\
\text { cases }\end{array}$ & $\%$ & $\begin{array}{l}\text { No. of } \\
\text { cases }\end{array}$ & $\%$ \\
\hline $\begin{array}{l}\text { Preterm } \\
(29) \\
\text { Small-for-dates } \\
(27) \\
\text { Normal-for- } \\
\text { dates (75) }\end{array}$ & $\begin{array}{l}18 \\
63\end{array}$ & $\begin{array}{l}31 \\
67 \\
84\end{array}$ & $\begin{array}{r}9 \\
12\end{array}$ & 34 \\
\hline Total (131) & 90 & 68 & 41 & 32 \\
\hline
\end{tabular}

weighing more than $2.5 \mathrm{~kg}$ (63 out of $75,84 \%$ ) $\left(x^{2}=3.52 ; \mathrm{P}<0.05\right)$. However, only 9 out of 29 preterm babies had a primary repair, the difference from small-for-dates babies being significant $\left(\chi^{2}=5 \cdot 73 ; 0 \cdot 05<P<0.01\right)$. Of 102 term infants, $21(20 \cdot 6 \%)$ were treated by staged procedures, mainly because of the wide gap between the two segments of the oesophagus. Of all the patients in whom operative treatment was staged about half were preterm, and nearly all had severe additional anomalies.

Mortality (Table II) was similar for all babies

\section{TABLE II}

Operative procedures and mortality related to intrauterine growth in 131 babies with oesophageal atresia

\begin{tabular}{|c|c|c|c|c|c|c|}
\hline & \multicolumn{3}{|c|}{$\begin{array}{l}\text { Primary repair } \\
\text { ( } 90 \text { babies) }\end{array}$} & \multicolumn{3}{|c|}{$\begin{array}{l}\text { Staged procedures } \\
\text { (41 babies) }\end{array}$} \\
\hline & Cases & Deaths & $\%$ & Cases & Deaths & $\%$ \\
\hline $\begin{array}{l}\text { Pre-term } \\
\text { Small-for-dates } \\
\text { Normal-for- } \\
\text { dates }\end{array}$ & $\begin{array}{r}9 \\
18 \\
63\end{array}$ & $\begin{array}{l}2 \\
3 \\
9\end{array}$ & $\begin{array}{l}22 \\
17 \\
\\
14\end{array}$ & $\begin{array}{r}20 \\
9 \\
12\end{array}$ & $\begin{array}{r}16 \\
6 \\
3\end{array}$ & $\begin{array}{l}80 \\
66 \\
25\end{array}$ \\
\hline
\end{tabular}

treated by primary anastomiosis. With staged operation the chance of survival was less. This difference was not significantly great between term infants of good size and those of low weight (Fisher's test $P>0.05$ ) but higher mortality occurred in preterm compared with term babies (Fisher's test $0.05>P>0.01)$.

\section{Discussion}

Some babies born with oesophageal atresia suffer from intrauterine growth retardation and a large series shows an unduly high proportion of infants of low birthweight. There is also an association between premature birth and a combination of oesophageal and other severe anomalies.

A baby weighing less than $2.5 \mathrm{~kg}$ at birth may survive without special care, but is subject to risks which are more frequent in low weight babies. The consequent complications must be identified and treated. A short gestation may be an even greater hazard than low birthweight because certain disorders of early life, such as hyaline membrane disease, are known to be more common in preterm babies.

In preterm babies with oesophageal atresia or tracheo-oesophageal fistula, there was the expected higher incidence of respiratory distress and, also a higher incidence of associated severe anomalies. The only relevant difference in term infants with oesophageal atresia or tracheo-oesophageal fistula was a higher incidence of pneumonia in small-for-dates babies. This may be because bronchi with a smaller lumen are more easily obstructed by oedema and spasm produced by inhalation of gastric acid. The effects of this complication can be reduced by intensive physiotherapy, chemotherapy, and by delaying operation for up to 48 hours.

About $70 \%$ of small-for-dates and $33 \%$ of preterm babies tolerated division of the fistula and primary oesophageal anastomosis, as well as goodsized term babies.

In preterm babies associated severe anomalies were a special lethal factor, the commonest being anorectal anomaly, congenital heart disease, or genitourinary anomaly. In the 60 patients treated between 1967 and 1973, $16(26 \%)$ died during the primary admission to hospital and 4 others died later either at home or after readmission. 4 died of severe respiratory distress or pneumonia before any treatment could be given; 5 others died of complications related to the operative treatment. In 7 death was directly related to severe associated anomalies. 6 of these were cardiovascular and of these 3 were probably not amenable to treatment. It is doubtful if early cardiovascular investigation will help in the management of babies with oeso- 
phageal atresia or tracheo-oesophageal fistula, since clinical signs of a circulatory anomaly may not be manifest in early life. However, when cyanosis is rot adequately explained by a respiratory lesion it is possible that the ECG might be of diagnostic value. On the other hand, the well known association of anorectal and genitourinary anomalies is a clear indication for intravenous pyelography before operation on a baby with both oesophageal atresia and an anorectal anomaly. When untreatable severe renal anomalies are found, even a gastrostomy is unjustified. When additional anomalies need early correction priority must be given to the most urgent problem which may not be the tracheo-oesophageal fistula and oesophageal atresia.

\section{REFERENCES}

Butler, N. R., and Bonham, D. G. (1963). Perinatal Mortality. Livingstone, Edinburgh

Cozzi, F., and Wilkinson, A. W. (1967). Oesophageal atresia. Lancet, 2, 1222.
Koop, C. E., and Hamilton, J. P. (1965). Atresia of the oesophagus: increased survival with staged procedures in the poor-risk infant. Annals of Surgery, 162, 389.

Lubchenco, L. O., Hansman, C., Dressler, M., and Boyd, E. (1963). Intrauterine growth as estimated from live born birthweight data at 24-42 weeks of gestation. Pediatrics, 32, 793.

Myers, N. (1974). Oesophageal atresia: the epitome of modern surgery. Annals of the Royal College of Surgeons of England, $54,277$.

Waterston, D. J., Bonham Carter, R. E., and Aberdeen, E. (1962). Oesophageal atresia: tracheo-oesophageal fistula. A study of survival in 218 infants. Lancet, $1,819$.

World Health Organization (1961). Public health aspects of low birth-weight. Technical Report, Series No. 217. W.H.O., Geneva.

Working Party to Discuss Nomenclature Based on Gestational Age and Birth Weight. (1971). Perinatal Medicine: Procedings of 2nd European Congress on Perinatal Medicine, London, 1970 p. 172. Ed. by P. J. Huntingford, R. W. Beard, F. E. Hytten, and J. W. Scopes. Karger, Basle.

Correspondence to Professor A. W. Wilkinson, Institute of Child Health, 30 Guilford St., London WC1N 1EH. 
Oxygen consumption and evaporative water loss in infants with congenital heart disease

Varga, F. (1959). The respective effects of starvation and changed body composition on energy metabolism in malnourished infants. Pediatrics, 23, 1085.

Wessel, H. U., Rorem, D., Muster, A. J., Acevedo, R. E., and Paul, M. H. (1969). Continuous determination of oxygen uptake in sedated infants and children during cardiac catheterization. American fournal of Cardiology, 24, 376.
Wood, J. E., Litter, J., and Wilkins, R. W. (1956). Peripheral vasoconstriction in human congestive heart failure. Circulation, 13, 524.

Correspondence to Dr. D. L. Kennaird, Woodlands, Lustleigh, Newton Abbot, Devon TQ13 9TE.

Corrigenda: 'Low birthweight babies with oesophageal atresia or tracheo-oesophageal fistula.' By F. Cozzi and $A$. W. Wilkinson, October 1975, 50, 791.

(1) p. 791 under 'Uterine growth' line 3 should read, '... with a mean weight of $2.08 \mathrm{~kg}, \ldots$,

(2) p. 792 under 'Deaths' line 2 should read, ' 1 out of 16 was born between 1959 and 1967 and 7 out of 14 were born between 1967 and 1973.' 